\section{Recent advances in the treatment of gastrointestinal stromal tumors}

\author{
César Serrano and Suzanne George
}

Ther Adv Med Oncol 2014, Vol. 6(3) 115-127 DOI: $10.1177 /$ 1758834014522491

(c) The Author(s), 2014. Reprints and permissions: http://www.sagepub.co.uk/ journalsPermissions.nav

\begin{abstract}
Constitutively activating mutations in the KIT and platelet-derived growth factor receptor $\alpha$ (PDGFRA) RTKs play a crucial role in the biology of gastrointestinal stromal tumors (GISTs), and this disease has served as an effective model for targeting gain-of-function kinase mutations in cancer. Imatinib has entered the clinical arena in the last decade and substantially improved the outcome in these formerly untreatable cancers. However, most advanced GISTs responding to imatinib progress within 2-3 years due to heterogeneous subclones harboring a range of imatinib-resistant secondary KIT mutations. Sunitinib, and more recently, regorafenib, have obtained US Food and Drug Administration approval for the treatment of GISTs after imatinib failure, and thus expanded the treatment options in resistant disease. Within this framework, we present an evaluation of current GIST management, emphasizing the most recent advances in the field together with a discussion on future steps to be taken in refractory disease.
\end{abstract}

Keywords: C-KIT, gastrointestinal stromal tumors, imatinib, masitinib, nilotinib, regorafenib, sorafenib, sunitinib

\section{Introduction}

Novel insights into the biology of gastrointestinal stromal tumors (GISTs) have revolutionized the therapeutic options for management of both localized and advanced GISTs. It was not until 1998 that Hirota and colleagues identified gain-of-function mutations of the receptor tyrosine kinase (RTK) KIT in the majority of GISTs as the primary oncogenic driver of the disease [Hirota et al. 1998]. Platelet-derived growth factor receptor $\alpha$ (PDGFRA)-activating mutations were also reported shortly thereafter and found mutually exclusive with KIT mutations [Heinrich et al. 2003b]. GISTs have therefore emerged as a solid paradigm of RTKdriven tumors in which strategies that inhibit the oncogenic kinase lead to significant disease control.

This review provides an overview of the current treatment strategies in GISTs and emphasizes the major therapeutic breakthroughs that have been achieved in recent years.
Imatinib, sunitinib and regorafenib are standards of care in advanced and metastatic GISTs

\section{Molecular biology of GISTS}

GISTs are the most common primary mesenchymal tumors of the gastrointestinal tract [Fletcher et al. 2002; Joensuu et al. 2002] and are characterized by expression of KIT (CD117) in approximately $95 \%$ of cases. Constitutive activation of KIT occurs in approximately $80-85 \%$ of GIST cases through activating mutations in the KIT gene and constitutes one of the earliest transforming events in GISTs [Corless et al. 2002]. Activating mutations of the KIT gene in GISTs occur most frequently in KIT exon 11 (juxtamembrane domain), followed by KIT exon 9 (extracellular domain) (Figure 1). Less frequently, primary mutations in the adenosine triphosphate (ATP)-binding pocket (exon 13) or activation loop (exon 17) are found [Corless et al. 2011]. Primary PDGFRA mutations in the juxtamembrane domain (exon 12), the first tyrosine kinase
Correspondence to: Suzanne George, MD Center for Sarcoma and Bone Oncology, DanaFarber Cancer Institute/ Harvard Medical School, 450 Brookline Ave. Boston, MA 02215, USA sgeorge2Apartners.org César Serrano, MD Center for Sarcoma and Bone Oncology, DanaFarber Cancer Institute/ Harvard Medical School, Boston, MA, USA cserrano2apartners.org 


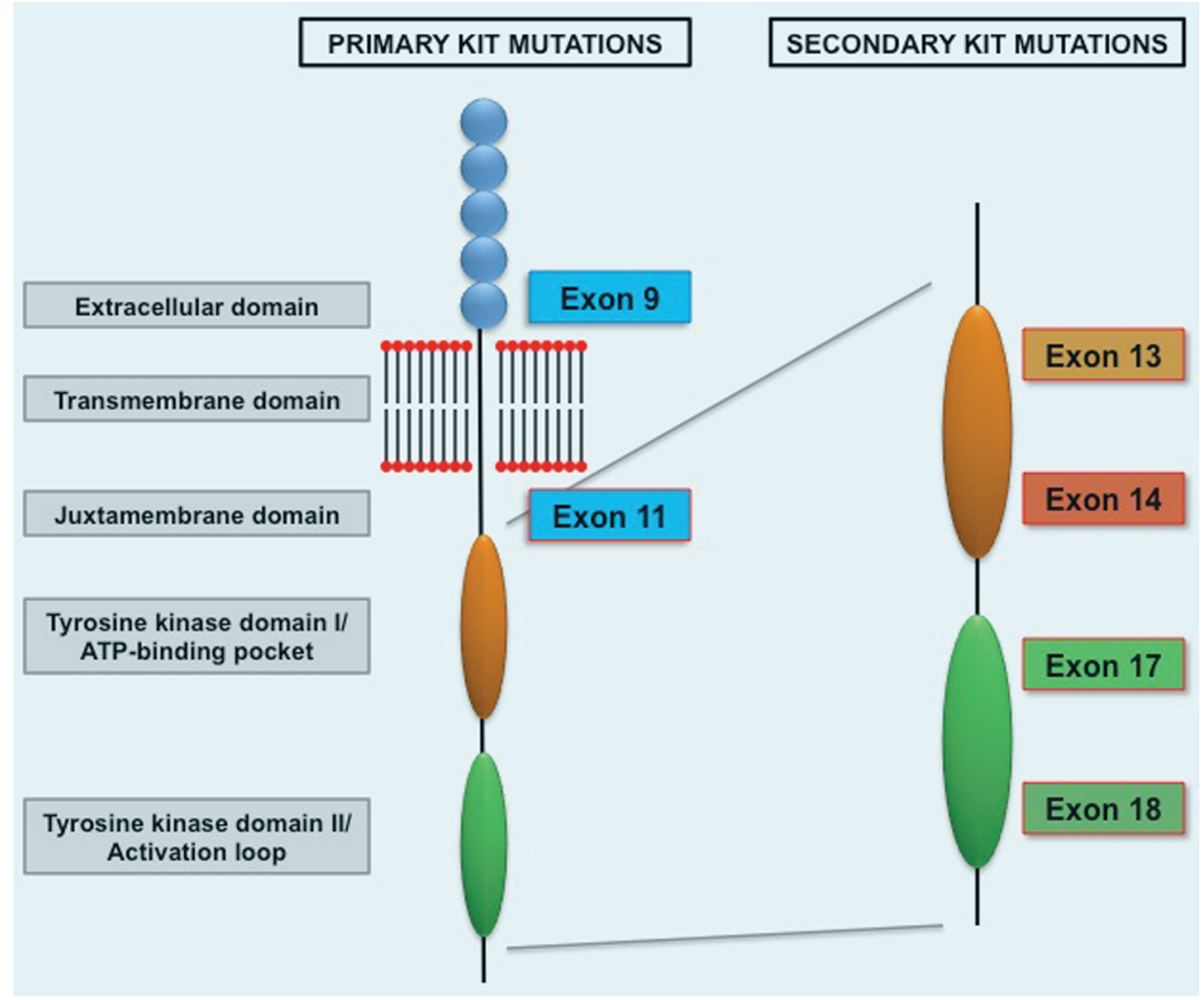

Figure 1. KIT activation in gastrointestinal stromal tumors. ATP, adenosine triphosphatase.

domain (exon 14), and the activation loop (exon 18) are also associated with the pathogenesis of GISTs in approximately $5-7 \%$ of cases [Cassier et al. 2012; Corless et al. 2005].

Downstream PI3K/AKT and RAS/RAF/mitogen-activated protein kinase (MAPK) pathways are constitutively active in GIST models and cell lines in a KIT-dependent manner through direct interaction with signal intermediates PI3K and GRB2 [Duensing et al. 2004; Zhu et al. 2007]. In vitro pharmacological studies have corroborated the importance of these two signaling cascades in both imatinib-sensitive and imatinib-resistant GISTs [Bauer et al. 2007]. Particularly, KIT activation of the MAPK pathway is crucial to stabilize ETS translocation variant 1 (ETV1), a lineage survival transcription factor indispensable for oncogenic KIT-mediated transformation [Chi et al. 2010].

\section{Imatinib: first-line treatment in advanced/} metastatic GISTS

Imatinib (Gleevec in USA, Glivec elsewhere; Novartis Oncology, Basel), a small molecule tyrosine kinase inhibitor (TKI) with activity against KIT, PDGFR and ABL kinase, was the first TKI approved by the US Food and Drug Administration (FDA) for the treatment of metastatic or unresectable GISTs following the demonstration of sustained response to imatinib $400 \mathrm{mg}$ daily in an open-label, randomized, multicenter phase II trial [Demetri et al. 2002]. After follow up of 71 months, approximately two-thirds of the patients had objective radiographic response to imatinib, and an additional $15 \%$ of patients experienced prolonged stable disease [Blanke et al. 2008a; Demetri et al. 2002] (Table 1). Patients with stable disease had similar long-term benefit and favorable survival outcomes as those with objective responses [Blanke et al. 2008a]. The median time to progression (mTTP) was 24 months, and median overall survival (mOS) for all patients studied was 57 months, superior to that achieved in the pre-imatinib era, typically around 10-20 months [Joensuu et al. 2002]. Patients with KIT exon 11 mutation had a substantially greater likelihood of a partial response and longer time to treatment failure compared with patients with either an exon 9 mutation or 
Table 1. Comparative activity of imatinib, sunitinib, regorafenib and imatinib rechallenge in patients with advanced or metastatic gastrointestinal stromal tumor.

\begin{tabular}{llccc} 
& $\begin{array}{l}\text { Imatinib }(n=147) \\
\text { [Blanke et al. 2008a] }\end{array}$ & $\begin{array}{l}\text { Sunitinib }(n=207) \\
\text { [Demetri et al. 2012] }\end{array}$ & $\begin{array}{l}\text { Regorafenib }(n=133) \\
\text { [Demetri et al. 2013] }\end{array}$ & $\begin{array}{l}\text { Imatinib rechallenge ( } n=41 \text { ) } \\
\text { [Kang et al. 2013] }\end{array}$ \\
\hline ORR (\%) & 68.1 & 7 & 4.5 & 0 \\
SD 12 weeks $(\%)$ & 15.6 & 53 & 48.1 & 32 \\
TTP/PFS (months) & 24 & 6.1 & 4.8 & 1.8 \\
\hline ORR includes complete response and partial response. & \\
ORR, overall response rate; PFS, progression-free survival; SD, stable disease; TTP, time to treatment progression.
\end{tabular}

no detectable mutation in either KIT or PDGFRA [Heinrich et al. 2003a].

Two phase III trials further confirmed the benefit of imatinib in GIST and also studied the efficacy of higher imatinib doses (800 versus $400 \mathrm{mg}$ daily) [Blanke et al. 2008b; Verweij et al. 2004]. Overall, a small but statistically significant progression-free survival (PFS) advantage was seen with the higher dose, with no difference in overall survival between the two arms. Notably, the presence of KIT exon 9 mutation was the only significant predictive factor for benefit from higher doses [MetaGIST 2010], whereas patients with tumors which harbor KIT exon 11 mutation, did not benefit from higherdose imatinib. Therapy was well tolerated, with mild diarrhea, edema and fatigue being the most common treatment-related toxicities. Patients on higher-dose therapy reported more side effects.

Unless significant toxicities occur, continuous therapy until disease progression is recommended, since interruption of imatinib results in disease progression within 12 months in most patients [Patrikidou et al. 2013]. Remarkably, a subset of patients with GIST have demonstrated 10 years of disease control, as shown in a preliminary report from the initial phase II trial, in which $18 \%$ of the patients survived long term on firstline imatinib since study entry, at a median follow up of 9.4 years [von Mehren et al. 2011]. The only prognostic factor predictive of longer TTP was low volume of disease at baseline.

Nonetheless, the vast majority of patients with advanced GISTs who benefit from imatinib have persistent measurable disease and eventually progressive disease, typically within $2-3$ years. The most common mechanism of resistance to TKIs in patients with GIST entails expansion of tumor clones harboring a range of secondary mutations in KIT or PDGFRA which are resistant to imatinib. KIT TKI-resistant mutations in GISTs cluster in two regions of the KIT kinase domain: the ATP-binding pocket (encoded by exons 13 and 14), and the activation loop (encoded by exons 17 and 18), and these mutations occur almost exclusively in the same gene and allele as the primary oncogenic driver mutation [Antonescu et al. 2005; biec-Rychter et al. 2005; Chen et al. 2004; Heinrich et al. 2006] (Figure 1). Moreover, there is substantial heterogeneity of secondary resistant mutations between and within metastases from individual patients, which underscores the complexity of the TKI-resistant population and emerges as the main treatment challenge in patients with GIST after frontline imatinib treatment [Liegl et al. 2008; Wardelmann et al. 2005].

\section{Sunitinib: second-line treatment in patients with GIST after failure of or intolerance to imatinib}

Following failure of imatinib, sunitinib (Sutent; Pfizer Inc., New York, USA), a multitargeted small-molecule TKI with potent activity against KIT and PDGFRA, among several other kinases, has been shown to be an effective second-line therapy and is currently approved worldwide for metastatic GISTs in patients with imatinib resistance or intolerance. In a pivotal randomized, double-blind, placebo-controlled phase III trial in patients with imatinib-refractory or -intolerant GISTs, 312 patients were enrolled and randomized to receive sunitinib or placebo. Sunitinib dose was $50 \mathrm{mg}$ daily, 4 weeks on, 2 weeks off. Despite a low objective response rate in the sunitinib group ( $7 \%$ response rate), TTP, the primary endpoint, was fourfold higher in the sunitinib arm compared with placebo, 27 weeks versus 6 weeks respectively (Table 1) [Demetri et al. 2006, 2012].

Continuous daily dosing of sunitinib $37.5 \mathrm{mg}$ has also shown activity in an open-label phase II 
clinical trial in 61 patients with GIST resistant or intolerant to imatinib, with a clinical benefit rate of $53 \%$ ( $13 \%$ response rate), and mPFS of 34 weeks [George et al. 2009].

Due to the wider spectrum of target inhibition, the range of side effects of sunitinib is greater than those for imatinib, although the majority are mild to moderate in severity and manageable through dose modification or interruption. The most commonly reported treatment-related adverse events were fatigue, diarrhea, skin discoloration, and nausea [Demetri et al. 2006; George et al. 2009].

As with imatinib, resistance to sunitinib develops, likely secondary to resistant KIT mutations. GIST kinase genotype after imatinib failure correlates with sunitinib activity. First, clinical benefit, $\mathrm{mPFS}$ and $\mathrm{mOS}$ were significantly higher for those with a primary KIT exon 9 or wild-type KIT/PDGFRA mutation. Second, there was also correlation between secondary KIT mutations and response to sunitinib: while KIT ATPbinding pocket mutations are exquisitely sensitive to sunitinib, the activation loop mutations are cross resistant [Heinrich et al. 2008].

\section{Regorafenib: a recent standard of care for GISTS}

Regorafenib (Stirvarga, Bayer HealthCare Pharmaceuticals Inc., Montville, NJ, USA) is an orally active multikinase inhibitor with activity against a variety of kinases, including those involved in oncogenesis (KIT, RET, RAF1, BRAF and BRAF V600E), regulation of tumor angiogenesis (VEGFR1-3 and TEK), and the tumor microenvironment (PDGFR and fibroblast growth factor receptor). Regorafenib has shown potent antitumor activity in a variety of preclinical models, including inhibition of growth of GIST cell lines, and inhibition of tumor growth as well as antimetastatic activity in several mouse xenografts, including some GIST xenograft models [Wilhelm et al. 2011].

Regorafenib, as a single agent, has been evaluated in renal cell carcinoma, colorectal cancer and GIST. The recommended dose is $160 \mathrm{mg}$ taken orally once daily for the first 21 days of each 28 -day cycle. Cycles are typically continued until disease progression or unacceptable toxicity. Regorafenib was first evaluated in an academicinitiated phase II clinical trial in patients with
TKI-refractory GIST [George et al. 2012]. Clinical benefit rate, as defined by the composite of complete response (CR), partial response (PR) and stable disease (SD) lasting at least 16 weeks, was the primary endpoint of the study and resulted in four PRs and 22 SDs (26 of 33 evaluable patients). mPFS for the entire cohort was 10.0 months.

Based on these promising results, an international, randomized (2:1), placebo-controlled, multicenter, phase III trial (GRID trial) was performed. In this trial a total of 199 patients with advanced GIST previously treated with at least imatinib and sunitinib were randomized: 133 GISTs were randomized to regorafenib as a single agent, and 66 to placebo [Demetri et al. 2013]. The primary endpoint of the study was PFS. At the time of disease progression, patients were unblinded, and if on placebo, allowed to crossover to regorafenib at the investigator's discretion. A statistically significant improvement in PFS was demonstrated among patients treated with regorafenib compared with placebo at 3 months. PFS at 3 months was $60 \%$ for regorafenib and $11 \%$ for placebo; and at 6 months, 38\% versus $0 \%$. Median PFS was also statistically significantly longer for patients treated with regorafenib: 4.8 months compared with 0.9 months in the placebo group [hazard ratio (HR) $0 \cdot 27,95 \%$ confidence interval (CI) $0 \cdot 19-0 \cdot 39$; $p<0.0001)$. No difference was observed in mOS between the groups due to the crossover design. Benefit of regorafenib on centrally assessed PFS was identified across all subgroups, except for the small subset of patients with duration of imatinib treatment of less than 6 months. As observed with sunitinib, overall response rate was low, $4.5 \%$, with primary benefit seen as SD which was seen as best response at any time in, $71.4 \%$ of study participants randomized to regorafenib compared with $33.3 \%$ of patients in the placebo arm. Disease control rate, defined as CR, PR or SD at 12 weeks was $52.6 \%$ for patients treated with regorafenib (Table 1) and $9.1 \%$ of those treated with placebo (95\% CI $-54 \cdot 72$ to $-32 \cdot 49 ; p<0 \cdot 0001)$.

The toxicity profile of regorafenib was consistent with that of other kinase inhibitors with similar target spectrum. The most common adverse events were hand-foot skin reaction, hypertension, diarrhea, fatigue, and oral mucositis.

Adverse events grade 3 or higher were reported in $61 \%$ of patients receiving regorafenib, and the most common were hypertension and hand-foot 
skin reaction. Overall, dose interruptions and dose reductions for adverse events were required in $58 \%$ and $50 \%$ of patients receiving regorafenib, but the rate of treatment discontinuation was low $(2.3 \%)$.

Based on these results, regorafenib obtained FDA approval in February 2013 for the treatment of metastatic or unresectable GIST after failure or intolerance to imatinib and sunitinib.

\section{Imatinib rechallenge as an alternative therapeutic strategy after failure of imatinib and sunitinib}

Despite the remarkable advances in therapeutic options for advanced GIST, disease progression occurs in the majority of patients following use of imatinib, sunitinib and regorafenib. Resumption of imatinib with palliative purposes has been a common practice in spite of prior failure, mainly based on the evidence of rapid progression and symptom worsening after TKI discontinuation. The randomized, double-blind, placebo-controlled, phase III RIGHT trial formally addressed this question in patients with imatinib-refractory GIST who had progressed to receiving at least imatinib and sunitinib, but had achieved prior benefit with imatinib in the first-line setting [Kang et al. 2013].

A total of 81 patients were randomized $1: 1$ to receive imatinib $400 \mathrm{mg}$ daily or placebo after failure of at least imatinib and sunitinib. Imatinib was well tolerated, and PFS was found to be significantly longer in the imatinib arm compared with placebo, 1.8 months versus 0.9 months, together with a disease control rate at 12 weeks of $32 \%$ (Table 1). There were no significant improvements in objective response and overall survival.

Therefore, it is hypothesized that the benefit observed with the rechallenge of imatinib in TKIrefractory GIST is due to continuous kinase inhibition of the bulk of disease clones that have not acquired secondary resistant mutations, although resistant clones continue to grow, as observed from the short PFS.

Newer therapies in TKI-refractory GISTs are an unmet clinical need, and we encourage treating these patients in clinical trials. Rechallenge of imatinib may serve as a useful therapeutic approach to palliate and minimize symptom worsening in GISTs when additional options are no longer available, although no data on quality of life were presented in the RIGHT trial.

\section{Other targeted agents in GISTs}

Despite the demonstrated success of imatinib, sunitinib and regorafenib, virtually all patients with metastatic GIST will become resistant to these therapies. Furthermore, the polyclonal evolution of resistant clones after progression to imatinib leads to a drop in the efficacy of subsequent lines, such as sunitinib and regorafenib. Several other TKIs have been tested in this setting (Table 2), but in some cases the studies have found only limited activity, and in other cases, there are limited data to support widespread use in the clinic.

Sorafenib (Nexavar, Bayer Healthcare Pharmaceuticals and ONYX Pharmaceuticals, San Francisco, CA, USA) is a by-aryl urea multikinase inhibitor closely related to regorafenib, with activity against KIT and PDGFRA among several other kinases. Two single-arm phase II clinical trials have demonstrated activity in patients with GIST after progression to at least imatinib and sunitinib, with an overall response rate of approximately $10 \%$ and disease control rate at 24 weeks of $36 \%$. mPFS in both trials was around 5 months [Park et al. 2012; Kindler et al. 2013]. Similarly to sunitinib, the activity of sorafenib in GIST is due to inhibition of KIT activity in both KIT primary and secondary mutations, as assessed in vitro in transfected KIT constructs and GIST cell lines [Heinrich et al. 2012a].

Nilotinib (Tasigna; Novartis Pharma AG, Basel) is a second-generation KIT and PDGFRA inhibitor derived from imatinib. In vitro activity of nilotinib is greater than imatinib against BRC-ABL, but comparable regarding KIT/PDGFRA inhibition [Weisberg et al. 2005], although nilotinib passive intracellular transport results in a 7 - to 10-fold higher intracellular concentration in imatinib-sensitive and -resistant cell lines [Prenen et al. 2006].

Results from a phase I study, two phase II studies and a compassionate use program [Cauchi et al. 2012; Demetri et al. 2009; Montemurro et al. 2009; Sawaki et al. 2011] provided preliminary evidence of clinical benefit in TKI-refractory GIST. However, two later randomized phase III studies have failed to demonstrate significant 
Table 2. Tyrosine kinase inhibitors with KIT inhibitory activity tested in clinical trials in patients with gastrointestinal stromal tumor.

\begin{tabular}{lllllll}
\hline & Study & Setting & Phase & N & ORR (\%) & PFS (months) \\
\hline Sorafenib & Park et al. [2012] & ZThird line & II & 31 & 13 & 4.9 \\
& Kindler et al. [2011] & ZSecond line & II & 38 & 13 & 5.2 \\
Nilotinib & Cauchi et al. [2012] & Third line & II & 13 & 0 & 6 \\
& Sawaki et al. [2011] & Third line & II & 35 & 3 & 3.7 \\
& Reichardt et al. [2012] & Third line & III & 165 & $<1$ & 3.6 \\
\multirow{2}{*}{$\begin{array}{l}\text { Masitinib } \\
\text { N. number of patients treated with the corresponding drug; NA, not available; ORR, overall response rate; PFS, } \\
\text { progression-free survival. }\end{array}$} & First line & III & 324 & NA & 25.9 \\
\hline
\end{tabular}

activity in either the first- or third-line setting [Reichardt et al. 2012; Blay et al. 2013].

Dasatinib (Sprycel; Bristol-Myers Squibb, New York, USA) was developed as a dual SRC/ABL inhibitor with activity against other kinases including KIT, with the particularity that dasatinib is able to bind to KIT regardless of the conformation of the KIT activation loop [Bantscheff et al. 2007]. Dasatinib has been investigated in TKI-naïve GIST in a single-arm phase II clinical trial, but the trial was terminated earlier due to slow accrual. Activity reported from 43 eligible patients showed $67 \%$ of FDG-PET response rate at 4 weeks, and a mPFS of 11 months [Montemurro et al. 2012].

Masitinib mesylate (AB1010; AB Sciences, Paris, France) is an orally available TKI with greater activity and selectivity than imatinib against KIT exon 11 mutant and wild-type KIT receptor [Soria et al. 2009]. Masitinib showed encouraging activity in a subset of patients with GIST in a phase I clinical trial [Soria et al. 2009], and particularly later in a pilot phase II study in 30 patients with metastatic imatinib-naïve GIST [Le Cesne et al. 2010]. In this study, masitinib obtained comparable results to imatinib in terms of responses and tolerability: 29 out of 30 patients achieved disease control, and MPFS was 41.3 months. Masitinib is currently being compared in the first-line setting with imatinib in a randomized phase III clinical trial [ClinicalTrials.gov identifier: NCT00812240] [Montemurro et al. 2012].

\section{Adjuvant and neoadjuvant imatinib}

The success of imatinib in advanced disease prompted interest in its perioperative use, which includes both preoperative therapy for patients with unresectable or borderline resectable tumors, and postoperative treatment for patients at high risk of recurrence after complete resection of a primary GIST tumor.

\section{Adjuvant treatment of GISTS}

Complete resection is possible in most localized GISTs and constitutes the current standard of care. Although a significant proportion of patients will be cured with surgery alone, approximately $40 \%$ will eventually have relapsing disease, the great majority within the first 5 years. There are several criteria specifically created to better define the subset of patients with GIST with the highest likelihood of relapse and that could obtain more benefit from adjuvant treatment with imatinib. Among these risk-stratification schemes available for operable GIST, the most widely used are the National Institutes of Health $(\mathrm{NIH})$ consensus classification [Fletcher et al. 2002], the Armed Forces Institute of Pathology classification [Miettinen et al. 2001, 2005, 2006], and the modified NIH classification [Joensuu 2008]. Tumor size, mitotic count, and tumor site are well established risk factors for recurrence, and tumor rupture has later been associated independently with higher risk of recurrence. These three classifications were recently found to have roughly similar prognostic accuracy in a series of 2560 patients with completely resected GIST, none of whom received adjuvant imatinib [Joensuu et al. 2012b]. Notably, regardless of the classification scheme used, patients identified as intermediate risk had a clinical course that was similar to the low-risk group, suggesting that only the high-risk group follows a more aggressive course and would be the target population to consider for adjuvant treatments. 
Three randomized phase III clinical trials have evaluated the role of imatinib $400 \mathrm{mg}$ daily in the adjuvant setting for 1, 2 and 3 years [DeMatteo et al. 2009; Joensuu et al. 2012a; Casali et al. 2013], and all of them have demonstrated that adjuvant imatinib prolongs recurrence-free survival (RFS) compared with placebo. Additionally, the results provided by the SSG XVIII study demonstrate that 3 years of imatinib significantly improves RFS and overall survival compared with 1 year of therapy. However, benefit on RFS appears to be more evident during imatinib treatment and shortly thereafter, whereas the curves tend to overlap with longer follow up, as disease recurrence increases within 6-12 months after discontinuing adjuvant imatinib, regardless of the length of the treatment. This finding therefore raises the question of mechanism of action of adjuvant imatinib in GIST, as it is not known whether recurrences are truly being prevented or just delayed. Together, current evidence supports at least 3 years of adjuvant imatinib as a new standard for patients with resected, high-risk GIST, although the optimal duration of therapy remains unknown.

Future studies should focus on clarifying this and other areas of uncertainty. For instance, preliminary data from the EORTC62024 trial reported no difference in the imatinib failure-free survival endpoint with 2 years of adjuvant imatinib compared with placebo. Finally, whether doses greater than $400 \mathrm{mg}$ should be used in the adjuvant setting, or whether only high-risk patients derive benefit from adjuvant imatinib, will require prospective study.

\section{Neoadjuvant imatinib in GISTS}

Based on the high rate of responses observed with imatinib in patients with metastatic GIST, preoperative use of imatinib aims to reduce tumor bulk to facilitate complete surgical resection or increase the likelihood of organ preservation of initially unresectable or borderline resectable disease.

There are no randomized trials evaluating the benefit of neoadjuvant imatinib, but data from retrospective series and a few prospective phase II trials [Eisenberg et al. 2009; McAuliffe et al. 2009; Hohenberger et al. 2009] suggest that preoperative imatinib can reduce tumor size and permit later surgery in patients with locally advanced GIST. Long-term outcome appears to be comparable to a standard population of patients with GIST [Rutkowski et al. 2013].

Currently, National Comprehensive Cancer Network guidelines recommend initial (preoperative) treatment with imatinib in patients with marginally resectable tumors and in those with potentially resectable disease but with the risk of significant morbidity. Thus, those GISTs arising in anatomically compromised locations would be a preferred target population, and particularly rectal GISTs, that usually have responsive KIT exon 11 mutations and involve challenging surgeries [Jakob et al. 2013; Tielen et al. 2013].

\section{Future directions}

\section{KIT/PDGFR-mutant GISTS}

The past decade has led to discovery and understanding of crucial biological mechanisms that drive GIST survival and proliferation. This has led to the approval of three drugs (imatinib, sunitinib and regorafenib) for the treatment of advanced GIST, which have significantly improved survival in a disease formerly deemed resistant to all systemic therapies.

Drug treatment with imatinib causes substantial KIT inhibition and symptom palliation, together with a low rate of secondary effects. However, the great majority of patients develop resistance to first-line treatment due to secondary KIT mutations that lead to reactivation of KIT receptor and KIT downstream pathways in the presence of imatinib. One strategy could consist of maximizing the effect of imatinib and delay the appearance of resistant clones. Therefore, drug development of next-generation TKIs for KIT inhibition through irreversible binding (such as afatinib in epidermal growth factor receptor mutant non-small cell lung cancer) [Li et al. 2008] or conformational control inhibition (such as DCC-2036 in BCR-ABL chronic myeloid leukemia) [Chan et al. 2011] would constitute a major therapeutic advance with potential impact in both adjuvant and metastatic settings.

Imatinib-resistant GISTs are still dependent upon KIT signaling for survival and proliferation, as evidenced in GIST cell lines with KIT secondary mutations by decreased proliferation and increased apoptosis following inhibition of KIT activation by either RNA interference knockdown [Heinrich et al. 
Table 3. New drugs currently being tested in clinical trials in gastrointestinal stromal tumor.

\begin{tabular}{lll}
\hline Drugs & Phase & ClinicalTrials.gov identifier \\
\hline Tyrosine kinase inhibitors & & \\
Pazopanib & $\|$ & NCT01323400 \\
Ponatinib & $\|$ & NCT01874665 \\
XL820 & $\|$ & NCT00570635 \\
HSP90 inhibitors & & NCT01039519 \\
STA-9090 & NCT01294202 \\
Imatinib + AT13387 & II & NCT01404650 \\
AUY922 & & NCT01735968 \\
Combination treatments & I & NCT01468688 \\
Imatinib + BYL719 & I & NCT00455559 \\
Imatinib + BKM120 & II & \\
Imatinib + perifosine & & \\
\hline HSP90, heat shock protein 90. & & \\
\hline
\end{tabular}

2006], alternative KIT kinase inhibitors such as sunitinib [Heinrich et al. 2008] or heat shock protein 90 (HSP90) inhibitors [Bauer et al. 2006]. Novel strategies in imatinib-resistant GISTs have to address the inevitable intratumor heterogeneity by inhibiting KIT activation regardless of KIT genotype. In this sense, targeting HSP90 [Bauer et al. 2006] or the more selective HSP90 cofactor CDC37 [Marino-Enriquez et al. 2013] constitute two attractive approaches. Three HSP90 inhibitors (STA9090, AT-13387 and AUY922) are currently being tested in patients with GIST [ClinicalTrials. gov identifier: NCT01039519, NCT01294202, NCT01404650]. Other approaches include the wide range of TKIs with KIT inhibitory activity (see section Other targeted agents in GISTs). Among them, ponatinib, a next-generation TKI recently approved in imatinib-resistant BCR-ABL leukemia [Cortes et al. 2012] is currently being studied in a phase II clinical trial in patients with GIST [ClinicalTrials.govidentifier:NCT01874665] given its promising preclinical activity against KIT [Lierman et al. 2012]. Additionally, KIT downstream PI3K/AKT and RAS/RAF/MEK pathways emerge as two crucial targets regardless of KIT genotype. Indeed, recent in vitro and in vivo data [Bauer et al. 2007; Floris et al. 2013] suggest potent synergy of dual KIT and PI3K inhibition, and two ongoing clinical trials are investigating this combination in metastatic GIST [ClinicalTrials.gov identifier: NCT01735968, NCT01468688].

Current approved TKIs in GIST target both KIT and PDGFRA mutations, and the majority of PDGFRA-driven GISTs appear to benefit from these treatments, A notable exception, however, is the substitutions involving codon D842 in exon 18 of PDGFRA which is universally resistant to current approved KIT/PDGFRA inhibitors [Corless et al. 2005; Cassier et al. 2012]. Crenolanib is a potent inhibitor of imatinibresistant PDGFRA mutants in GISTs [Heinrich et al. 2012b], and a phase II clinical trial is ongoing to address the efficacy of this drug in this selected GIST subpopulation [ClinicalTrials.gov identifier: NCT01243346].

Finally, the efficacy of a monoclonal antibody against KIT has recently been demonstrated for the first time in vitro and in vivo [Edris et al. 2013]. Monoclonal antibody SR1 decreases proliferation, induces KIT downregulation and enhances cell-mediated tumor clearance, resulting in a novel approach for possible exploration in the treatment of GIST.

\section{Non-KIT/PDGFR-mutant GISTs I'wild-type" GISTS)}

It has long been recognized that a subset of GISTs do not harbor an activating mutation in either KIT or PDGFRA. These tumors have historically been classified as 'wild type' GISTs. Recently, it has become apparent that a wild-type GIST is composed of several subtypes of GIST, including GISTs associated with type I neurofibromatosis, and importantly, GISTs associated with Succinate dehydrogenase (SDH) deficiency (SDH-deficient GISTs) [Janeway et al. 2011; Killian et al. 2013]. Extensive discussion of these 
subtypes is beyond the scope of this review, however the recognition of these unique clinical and biologic subtypes of GIST is important due to the somewhat more indolent natural history of these tumors, predilection of younger age at presentation, high rate of metastasis, and decreased bidimensional response to imatinib. Additional studies to further define these subtypes and unique therapeutic strategies are ongoing. At this time, however, standard treatment with approved TKIs is recommended.

\section{Funding}

Cesar Serrano: American Society of Clinical Oncology (ASCO) Young Investigator Award.

\section{Conflict of interest statement}

The authors declare no conflicts of interest in preparing this article.

\section{Reference}

Antonescu, CR., Besmer, P., Guo, T., Arkun, K., Hom, G., Koryotowski, B. et al. (2005) Acquired resistance to imatinib in gastrointestinal stromal tumor occurs through secondary gene mutation. Clin Cancer Res, 11, 4182-4190.

Bantscheff, M., Eberhard, D., Abraham, Y., Bastuck, S., Boesche, M., Hobson, S. et al. (2007) Quantitative chemical proteomics reveals mechanisms of action of clinical ABL kinase inhibitors. Nat Biotechnol, 25, 1035-1044.

Bauer, S., Duensing, A., Demetri, GD. and Fletcher, JA. (2007) KIT oncogenic signaling mechanisms in imatinib-resistant gastrointestinal stromal tumor: PI3kinase/AKT is a crucial survival pathway. Oncogene, 26, 7560-7568.

Bauer, S., Yu, LK., Demetri, GD. and Fletcher, JA. (2006) Heat shock protein 90 inhibition in imatinibresistant gastrointestinal stromal tumor. Cancer Res, 66, 9153-9161.

Debiec-Rychter, M., Cools, J., Dumez, H., Sciot, R., Stul, M., Mentens, N. et al. (2005) Mechanisms of resistance to imatinib mesylate in gastrointestinal stromal tumors and activity of the PKC412 inhibitor against imatinib-resistant mutants. Gastroenterology, $128,270-279$.

Blanke, CD., Demetri, GD., Von Mehren, M., Heinrich, MC., Eisenberg, B., Fletcher, JA. et al. (2008a) Long-term results from a randomized phase II trial of standard- versus higher-dose imatinib mesylate for patients with unresectable or metastatic gastrointestinal stromal tumors expressing KIT. $\mathcal{F}$ Clin Oncol, 26, 620-625.
Blanke, CD., Rankin, C., Demetri, GD., Ryan, CW., Von Mehren, M., Benjamin, RS. et al. (2008b) Phase III randomized, intergroup trial assessing imatinib mesylate at two dose levels in patients with unresectable or metastatic gastrointestinal stromal tumors expressing the kit receptor tyrosine kinase: S0033. F Clin Oncol, 26, 626-632.

Blay, JY., Shen, L., Kang, YK., Rutkowski, P., Qin, S., Nosov, D. et al. Phase III trial of nilotinib versus imatinib as first-line targeted therapy of advanced gastrointestinal stromal tumors (GIST). J Clin Oncol 31, 2013 (suppl; abstr 10501^). http://meetinglibrary. asco.org/content/117861-132.

Casali, PG., Le Cesne, A., Poveda, A., Kotasek, D., Rutkowski, P., Hohenberger, P. et al. Imatinib failure-free survival (IFS) in patients with localized gastrointestinal stromal tumors (GIST) treated with adjuvant imatinib (IM): The EORTC/AGITG/FSG/ GEIS/ISG randomized controlled phase III trial. J Clin Oncol 31, 2013 (suppl; abstr 10500). http:// meetinglibrary.asco.org/content/114179-132.

Cassier, PA., Fumagalli, E., Rutkowski, P., Schoffski, P., Van, GM., Debiec-Rychter, M. et al. (2012) Outcome of patients with platelet-derived growth factor receptor alpha-mutated gastrointestinal stromal tumors in the tyrosine kinase inhibitor era. Clin Cancer Res, 18, 4458-4464.

Cauchi, C., Somaiah, N., Engstrom, PF., Litwin, S., Lopez, M., Lee, J. et al. (2012) Evaluation of nilotinib in advanced GIST previously treated with imatinib and sunitinib. Cancer Chemother Pharmacol, 69, 977-982.

Chan, WW., Wise, SC., Kaufman, MD., Ahn, YM., Ensinger, CL., Haack, T. et al. (2011) Conformational control inhibition of the BCR-ABL1 tyrosine kinase, including the gatekeeper T315I mutant, by the switch-control inhibitor DCC-2036. Cancer Cell, 19, 556-568.

Chen, LL., Trent, JC., Wu, EF., Fuller, GN., Ramdas, L., Zhang, W. et al. (2004) A missense mutation in KIT kinase domain 1 correlates with imatinib resistance in gastrointestinal stromal tumors. Cancer Res, 64, 5913-5919.

Chi, P., Chen, Y., Zhang, L., Guo, X., Wongvipat, J., Shamu, T. et al. (2010) ETV1 is a lineage survival factor that cooperates with KIT in gastrointestinal stromal tumours. Nature, 467, 849-853.

ClinicalTrials identifier: NCT00812240 A Phase 3 Study to Evaluate Efficacy and Safety of Masitinib in Comparison to Imatinib in Patients With GastroIntestinal Stromal Tumour in First Line Medical Treatment.

ClinicalTrials identifier: NCT01039519 A Study Evaluating STA-9090 in Patients With Metastatic and/or Unresectable Gastrointestinal Stromal Tumor (GIST). 
ClinicalTrials identifier: NCT01294202 A Study to Investigate the Safety and Efficacy of AT13387, Alone or in Combination With Imatinib, in Patients With GIST.

ClinicalTrials identifier: NCT01404650 Study of Hsp90 Inhibitor AUY922 for the Treatment of Patients With Refractory Gastrointestinal Stromal Tumor.

ClinicalTrials identifier: NCT01735968 A Dosefinding Study of a Combination of Imatinib and BYL719 in the Treatment of 3rd Line GIST Patients. 2013.

ClinicalTrials identifier: NCT01874665 A Phase 2 Trial of Ponatinib in Patients With Metastatic and/or Unresectable Gastrointestinal Stromal Tumor.

Clinica Trials identifier: NCT01468688 A Dosefinding Study of a Combination of Imatinib and BKM120 in the Treatment of 3rd Line GIST Patients.

Corless, CL., Barnett, CM. and Heinrich, MC. (2011) Gastrointestinal stromal tumours: origin and molecular oncology. Nat Rev Cancer, 11, 865-878.

Corless, CL., McGreevey, L., Haley, A., Town, A. and Heinrich, MC. (2002) KIT mutations are common in incidental gastrointestinal stromal tumors one centimeter or less in size. Am F Pathol, 160, 1567-1572.

Corless, CL., Schroeder, A., Griffith, D., Town, A., McGreevey, L., Harrell, P. et al. (2005) PDGFRA mutations in gastrointestinal stromal tumors: frequency, spectrum and in vitro sensitivity to imatinib. F Clin Oncol, 23, 5357-5364.

Cortes, JE., Kantariian, H., Shah, NP., Bixby, D., Mauro, MJ., Flinn, I. et al. (2012) Ponatinib in refractory Philadelphia chromosome-positive leukemias. N Engl F Med, 367, 2075-2088.

DeMatteo, RP., Ballman, KV., Antonescu, CR., Maki, RG., Pisters, PW., Demetri, GD. et al. (2009) Adjuvant imatinib mesylate after resection of localised, primary gastrointestinal stromal tumour: a randomised, double-blind, placebo-controlled trial. Lancet, 373, 1097-1104.

Demetri, GD., Casali, PG., Blay, JY., Von Mehren, M., Morgan, JA., Bertulli, R. et al. (2009) A phase I study of single-agent nilotinib or in combination with imatinib in patients with imatinib-resistant gastrointestinal stromal tumors. Clin Cancer Res, 15, 5910-5916.

Demetri, GD., Garrett, CR., Schoffski, P., Shah, MH., Verweij, J., Leyvraz, S. et al. (2012) Complete longitudinal analyses of the randomized, placebocontrolled, phase III trial of sunitinib in patients with gastrointestinal stromal tumor following imatinib failure. Clin Cancer Res, 18, 3170-3179.
Demetri, GD., Reichardt, P., Kang, YK., Blay, JY., Rutkowski, P., Gelderblom, H. et al. (2013) Efficacy and safety of regorafenib for advanced gastrointestinal stromal tumours after failure of imatinib and sunitinib (GRID): an international, multicentre, randomised, placebo-controlled, phase 3 trial. Lancet, 381, 295-302.

Demetri, GD., Van Oosterom, AT., Garrett, CR., Blackstein, ME., Shah, MH., Verweij, J. et al. (2006) Efficacy and safety of sunitinib in patients with advanced gastrointestinal stromal tumour after failure of imatinib: a randomised controlled trial. Lancet, 368, 1329-1338.

Demetri, GD., Von Mehren, M., Blanke, CD., Van den Abbeele, AD., Eisenberg, B., Roberts, PJ. et al. (2002) Efficacy and safety of imatinib mesylate in advanced gastrointestinal stromal tumors. $N$ Engl $\mathcal{F}$ Med, 347, 472-480.

Duensing, A., Medeiros, F., McConarty, B., Joseph, NE., Panigrahy, D., Singer, S. et al. (2004) Mechanisms of oncogenic KIT signal transduction in primary gastrointestinal stromal tumors (GISTs). Oncogene, 23, 3999-4006.

Edris, B., Willingham, SB., Weiskopf, K., Volkmer, AK., Volkmer, JP., Muhlenberg, T. et al. (2013) AntiKIT monoclonal antibody inhibits imatinib-resistant gastrointestinal stromal tumor growth. Proc Natl Acad Sci U S A, 110, 3501-3506.

Eisenberg, BL., Harris, J., Blanke, CD., Demetri, GD., Heinrich, MC., Watson, JC. et al. (2009) Phase II trial of neoadjuvant/adjuvant imatinib mesylate (IM) for advanced primary and metastatic/recurrent operable gastrointestinal stromal tumor (GIST): early results of RTOG 0132/ACRIN 6665. F Surg Oncol, 99, 42-47.

Fletcher, CD., Berman, JJ., Corless, C., Gorstein, F., Lasota, J., Longley, BJ. et al. (2002) Diagnosis of gastrointestinal stromal tumors: A consensus approach. Hum Pathol, 33, 459-465.

Floris, G., Wozniak, A., Sciot, R., Li, H., Friedman, L., Van, LT. et al. (2013) A potent combination of the novel PI3K Inhibitor, GDC-0941, with imatinib in gastrointestinal stromal tumor xenografts: long-lasting responses after treatment withdrawal. Clin Cancer Res, 19, 620-630.

George, S., Blay, JY., Casali, PG., Le Cesne, A., Stephenson, P., Deprimo, SE. et al. (2009) Clinical evaluation of continuous daily dosing of sunitinib malate in patients with advanced gastrointestinal stromal tumour after imatinib failure. Eur $\mathcal{F}$ Cancer, 45, 1959-1968.

George, S., Wang, Q., Heinrich, MC., Corless, CL., Zhu, M., Butrynski, JE. et al. (2012) Efficacy and safety of regorafenib in patients with metastatic and/or unresectable GI stromal tumor after failure of imatinib 
and sunitinib: a multicenter phase II trial. 7 Clin Oncol, 30, 2401-2407.

Heinrich, MC., Corless, CL., Blanke, CD., Demetri, GD., Joensuu, H., Roberts, PJ. et al. (2006) Molecular correlates of imatinib resistance in gastrointestinal stromal tumors. $\mathcal{F}$ Clin Oncol, 24, 4764-4774.

Heinrich, MC., Corless, CL., Demetri, GD., Blanke, CD., Von Mehren, M., Joensuu, H. et al. (2003a) Kinase mutations and imatinib response in patients with metastatic gastrointestinal stromal tumor. $\mathcal{F}$ Clin Oncol, 21, 4342-4349.

Heinrich, MC., Corless, CL., Duensing, A., McGreevey, L., Chen, CJ., Joseph, N. et al. (2003b) PDGFRA activating mutations in gastrointestinal stromal tumors. Science, 299, 708-710.

Heinrich, M., Griffith, D., McKinley, A., Patterson, J., Presnell, A., Ramachandran, A. et al. (2012b) Crenolanib inhibits the drug-resistant PDGFRA D842V mutation associated with imatinib-resistant gastrointestinal stromal tumors. Clin Cancer Res, 18:4375-4384.

Heinrich, MC., Maki, RG., Corless, CL., Antonescu, CR., Harlow, A., Griffith, D. et al. (2008) Primary and secondary kinase genotypes correlate with the biological and clinical activity of sunitinib in imatinibresistant gastrointestinal stromal tumor. $\mathcal{F}$ Clin Oncol, 26, 5352-5359.

Heinrich, MC., Marino-Enriquez, A., Presnell, A., Donsky, RS., Griffith, DJ., McKinley, A. et al. (2012a) Sorafenib inhibits many kinase mutations associated with drug-resistant gastrointestinal stromal tumors. Mol Cancer Ther, 11, 1770-1780.

Hirota, S., Isozaki, K., Moriyama, Y., Hashimoto, K., Nishida, T., Ishiguro, S. et al. (1998) Gain-offunction mutations of c-kit in human gastrointestinal stromal tumors. Science, 279, 577-580.

Hohenberger, P., Oladeji, O., Licht, T., Dimitrakopoulou-Strauss, A., Jakob, J., Pink, D. et al. Neoadjuvant imatinib and organ preservation in locally advanced gastrointestinal stromal tumors (GIST). J Clin Oncol 27:15s, 2009 (suppl; abstr 10550). http://meetinglibrary.asco.org/ content/33955-65.

Jakob, J., Mussi, C., Ronellenfitsch, U., Wardelmann, E., Negri, T., Gronchi et al. (2013) Gastrointestinal stromal tumor of the rectum: results of surgical and multimodality therapy in the era of imatinib. Ann Surg Oncol, 20, 586-592.

Janeway, K., Kim, S., Lodish, M., Nosé, V., Rustin, P., Gaal, J. et al. (2011) Defects in succinate dehydrogenase in gastrointestinal stromal tumorslacking KIT and PDGFRA mutations. Proc Natl Acad Sci USA 108:314-318.
Joensuu, H. (2008) Risk stratification of patients diagnosed with gastrointestinal stromal tumor. Hum Pathol, 39, 1411-1419.

Joensuu, H., Eriksson, M., Sundby, HK., Hartmann, JT., Pink, D., Schutte, J. et al. (2012a) Risk of recurrence of gastrointestinal stromal tumour after surgery: an analysis of pooled population-based cohorts. $\mathcal{F} A M A, 307,1265-1272$.

Joensuu, H., Fletcher, C., Dimitrijevic, S., Silberman, S., Roberts, P. and Demetri, G. (2002) Management of malignant gastrointestinal stromal tumours. Lancet Oncol, 3, 655-664.

Joensuu, H., Vehtari, A., Riihimaki, J., Nishida, T., Steigen, SE., Brabec, P. et al. (2012b) One vs three years of adjuvant imatinib for operable gastrointestinal stromal tumor: a randomized trial. Lancet Oncol, 13, 265-274.

Kang, YK., Ryu, MH., Ryoo, BY., Kim, HJ., Lee, JJ., Yoo, C. et al. Randomized phase III trial of imatinib (IM) rechallenge versus placebo (PL) in patients (pts) with metastatic and/or unresectable gastrointestinal stromal tumor (GIST) after failure of at least both IM and sunitinib (SU): RIGHT study. J.Clin. Oncol. 31 [ASCO Annual Meeting Proceedings]. http:// meeting.ascopubs.org/cgi/content/short/31/18_suppl/ LBA10502?rss $=1$.

Killian, J., Kim, S., Miettinen, M., Smith, C., Merino, M., Tsokos, M. et al. (2013) Cancer Discov 3:648-657.

Kindler, HL., Campbell, NP., Wroblewski, K., Maki, RG., D'Adamo, DR., Chow, WA. et al. Sorafenib (SOR) in patients (pts) with imatinib (IM) and sunitinib (SU)-resistant (RES) gastrointestinal stromal tumors (GIST): Final results of a University of Chicago Phase II Consortium trial. J Clin Oncol 29: 2011 (suppl; abstr 10009). http://meetinglibrary.asco. org/content/80567-102.

Le Cesne, A., Blay, JY., Bui, BN., Bouche, O., Adenis, A., Domont, J. et al. (2010) Phase II study of oral masitinib mesilate in imatinib-naive patients with locally advanced or metastatic gastro-intestinal stromal tumour (GIST). Eur F Cancer, 46, 1344 1351.

Li, D., Ambrogio, L., Shimamura, T., Kubo, S., Takahashi, M., Chirieac, LR. et al. (2008) BIBW2992, an irreversible EGFR/HER2 inhibitor highly effective in preclinical lung cancer models. Oncogene, 27, 4702-4711.

Liegl, B., Kepten, I., Le, C., Zhu, M., Demetri, GD., Heinrich, MC. et al. (2008) Heterogeneity of kinase inhibitor resistance mechanisms in GIST. F Pathol, 216, 64-74.

Lierman, E., Smits, S., Cools, J., Dewaele, B., Debiec-Rychter, M. and Vandenberghe, P. (2012) 
Ponatinib is active against imatinib-resistant mutants of FIP1L1-PDGFRA and KIT, and against FGFR1derived fusion kinases. Leukemia, 26, 1693-1695.

Marino-Enriquez, A., Ou, WB., Cowley, G., Luo, B., Jonker, AH., Mayeda, M. et al. (2013) Genomewide functional screening identifies CDC37 as a crucial HSP90-cofactor for KIT oncogenic expression in gastrointestinal stromal tumors. Oncogene [Epub ahead of print].

McAuliffe, JC., Hunt, KK., Lazar, AJ., Choi, H., Qiao, W., Thall, P. et al. (2009) A randomized, phase II study of preoperative plus postoperative imatinib in GIST: evidence of rapid radiographic response and temporal induction of tumor cell apoptosis. Ann Surg Oncol, 16, 910-919.

MetaGIST (2010) Comparison of two doses of imatinib for the treatment of unresectable or metastatic gastrointestinal stromal tumors: a meta-analysis of 1,640 patients. F Clin Oncol, 28, 1247-1253.

Miettinen, M., Furlong, M., Sarlomo-Rikala, M., Burke, A., Sobin, LH. and Lasota, J. (2001) Gastrointestinal stromal tumors, intramural leiomyomas, and leiomyosarcomas in the rectum and anus: a clinicopathologic, immunohistochemical, and molecular genetic study of 144 cases. Am F Surg Pathol, 25, 1121-1133.

Miettinen, M., Lasota, J. and Sobin, LH. (2005) Gastrointestinal stromal tumors of the stomach in children and young adults: a clinicopathologic, immunohistochemical, and molecular genetic study of 44 cases with long-term follow-up and review of the literature. Am f Surg Pathol, 29, 1373-1381.

Miettinen, M., Makhlouf, H., Sobin, LH. and Lasota, J. (2006) Gastrointestinal stromal tumors of the jejunum and ileum: a clinicopathologic, immunohistochemical, and molecular genetic study of 906 cases before imatinib with long-term follow-up. Am $\mathcal{F}$ Surg Pathol, 30, 477-489.

Montemurro, M., Domont, J., Blesius, A., Rutkowski, P., Roth, A., Van Moos, R. et al. Dasatinib firstline treatment in gastrointestinal stromal tumors: A multicenter phase II trial of the SAKK (SAKK 56/07). J Clin Oncol 30, 2012 (suppl; abstr 10033). http:// meetinglibrary.asco.org/content/96630-114.

Montemurro, M., Schoffski, P., Reichardt, P., Gelderblom, H., Schutte, J., Hartmann, JT. et al. (2009) Nilotinib in the treatment of advanced gastrointestinal stromal tumours resistant to both imatinib and sunitinib. Eur F Cancer, 45, 2293-2297.

Park, SH., Ryu, MH., Ryoo, BY., Im, SA., Kwon, HC., Lee, SS. et al. (2012) Sorafenib in patients with metastatic gastrointestinal stromal tumors who failed two or more prior tyrosine kinase inhibitors: a phase II study of Korean gastrointestinal stromal tumors study group. Invest New Drugs, 30, 2377-2383.
Patrikidou, A., Chabaud, S., Ray-Coquard, I., Bui, BN., Adenis, A., Rios, M. et al. (2013) Influence of imatinib interruption and rechallenge on the residual disease in patients with advanced GIST: results of the BFR14 prospective French Sarcoma Group randomised, phase III trial. Ann Oncol, 24, 10871093.

Prenen, H., Guetens, G., De, BG., Debiec-Rychter, M., Manley, P., Schoffski, P. et al. (2006). Cellular uptake of the tyrosine kinase inhibitors imatinib and AMN107 in gastrointestinal stromal tumor cell lines. Pharmacology, 77, 11-16.

Reichardt, P., Blay, JY., Gelderblom, H., Schlemmer, M., Demetri, GD., Bui-Nguyen, B. et al. (2012)

Phase III study of nilotinib versus best supportive care with or without a TKI in patients with gastrointestinal stromal tumors resistant to or intolerant of imatinib and sunitinib. Ann Oncol, 23, 1680-1687.

Rutkowski, P., Gronchi, A., Hohenberger, P., Bonvalot, S., Schoffski, P., Bauer, S. et al. (2013) Neoadjuvant imatinib in locally advanced gastrointestinal stromal tumors (GIST): the EORTC STBSG experience. Ann Surg Oncol, 20, 2937-2943.

Sawaki, A., Nishida, T., Doi, T., Yamada, Y., Komatsu, Y., Kanda, T. et al. (2011) Phase 2 study of nilotinib as third-line therapy for patients with gastrointestinal stromal tumor. Cancer, 117, 46334641 .

Soria, JC., Massard, C., Magne, N., Bader, T., Mansfield, CD., Blay, JY. et al. (2009) Phase 1 dose-escalation study of oral tyrosine kinase inhibitor masitinib in advanced and/or metastatic solid cancers. Eur $\mathcal{F}$ Cancer, 45, 2333-2341.

Tielen, R., Verhoef, C., Van, CF., Reyners, AK., Van der Graaf, WT., Bonenkamp, JJ. et al. (2013) Surgical management of rectal gastrointestinal stromal tumors. f Surg Oncol, 107, 320-323.

Verweij, J., Casali, PG., Zalcberg, J., Le Cesne, A., Reichardt, P., Blay, JY. et al. (2004) Progressionfree survival in gastrointestinal stromal tumours with high-dose imatinib: randomised trial. Lancet, 364, 1127-1134.

Von Mehren, M., Heinrich, MC., Joensuu, H., Blanke, CD., Wehre, E. and Demetri, GD. Follow-up results after 9 years (yrs) of the ongoing, phase II B2222 trial of imatinib mesylate (IM) in patients (pts) with metastatic or unresectable KIT+ gastrointestinal stromal tumors (GIST). Journal of Clinical Oncology 29. 2011. 2011 ASCO Annual Meeting, Abstract 10016.

Wardelmann, E., Thomas, N., Merkelbach-Bruse, S., Pauls, K., Speidel, N., Buttner, R. et al. (2005) Acquired resistance to imatinib in gastrointestinal stromal tumours caused by multiple KIT mutations. Lancet Oncol, 6, 249-251. 
Weisberg, E., Manley, PW., Breitenstein, W.,

Bruggen, J., Cowan-Jacob, SW., Ray, A. et al. (2005)

Characterization of AMN107, a selective inhibitor of native and mutant Bcr-Abl. Cancer Cell, 7, 129-141.

Wilhelm, SM., Dumas, J., Adnane, L., Lynch, M., Carter, CA., Schutz, G. et al. (2011) Regorafenib (BAY 73-4506): a new oral multikinase inhibitor of angiogenic, stromal and oncogenic receptor tyrosine kinases with potent preclinical antitumor activity. Int $\mathcal{F}$ Cancer, 129, 245-255.

Zhu, MJ., Ou, WB., Fletcher, CD., Cohen, PS., Demetri, GD. and Fletcher, JA. (2007) KIT oncoprotein interactions in gastrointestinal stromal tumors: therapeutic relevance. Oncogene, 26, 6386-6395.
Visit SAGE journals online http://tam.sagepub.com

(SAGE journals 